\title{
EVALUACIÓN DEL CONTENIDO DE ALMIDÓN EN PAPAS (SOLANUM TUBEROSUM, SP. TUBEROSUM CV. DESIRÉE), PRODUCIDAS EN FORMA ORGÁNICA Y CONVENCIONAL EN LA PROVINCIA DE CURICÓ, REGIÓN DEL MAULE
}

\author{
EVALUATION OF THE STARCH AMOUNT IN POTATOES \\ (SOLANUM TUBEROSUM, SP. TUBEROSUM CV. DESIRÉE), \\ PRODUCED IN ORGANIC AND CONVENTIONAL WAYS IN THE \\ PROVINCE OF CURICÓ, MAULE REGIÓN
}

Nelson Loyola L. ${ }^{1}$; Eduardo Oyarce C.; Carlos Acuña C. ${ }^{1}$

\section{RESUMEN}

Se evaluó la composición química de tubérculos de papas (Solanum tuberosum, sp. Tuberosum) cv. Desirée, producidos bajo dos formas de cultivo; convencional y orgánico; los componentes evaluados fueron: contenido de materia seca, almidón, proteínas, azúcares totales y azúcares reductores. Se usó un diseño completamente al azar y análisis de varianza con un $95 \%$ de exigencia para ver si existían diferencias estadísticas. El estudio concluyó en que no existieron diferencias significativas en los parámetros evaluados bajo las dos formas de cultivo. También se realizaron evaluaciones sensoriales de papas fritas con tubérculos producidos en forma convencional y orgánica, a los 30 y 75 días de poscosecha, participando 13 panelistas entrenados, quienes evaluaron los atributos de: color, textura y sabor. Para expresar los resultados se utilizaron gráficos del tipo radial, no encontrándose diferencias marcadas a favor de un tipo de papas, luego de freírlas, independiente del tipo de cultivo realizado, de acuerdo a los atributos evaluados.

Palabras clave: Solanum tuberosum, sp. Tuberosum, cultivo convencional, cultivo orgánico, composición química, evaluación sensorial

\section{ABSTRACT}

Chemical composition of potato tubers (Solanum tuberosum, sp. Tuberosum) cv. Desirée were evaluated after two production alternatives; conventional and organic, and the components were: dry matter content, starch, proteins, total and reducing sugars. A total randomized design was used and the values were measured by the anova with a 95\% of probability. There were no significant differences among the parameters evaluated under the two cultivation alternatives. Sensory evaluation with fried potato were also realized by using tubers from the two cultivation alternatives, conventional and organic, at 30 days and 75 days after harvest. Thirteen trained panelist participated, who evaluated the following attributes: color, texture and flavor. According to the panelist there were no differences in relation to any kind of potato tubers, after fried, whatever the cultivation alternatives, in relation to the sensory attributes.

Key words: Solanum tuberosum, sp. Tuberosum, conventional cultivation, organic cultivation, chemical composition, sensory evaluation.

\section{INTRODUCCIÓN}

La papa (Solanum tuberosum, sp. Tuberosum) es un cultivo que se ha ganado un espacio en la utilización de sus tubérculos como materia prima en la industria de alimentos, la cual establece requisitos rigurosos en parámetros de calidad (González, 2000). Las tendencias en el desarrollo tecnológico, referido al procesamiento de la papa en las últimas décadas, es sin duda importante, ya que ha orientado inversiones, procedimientos y equipos para acelerar el crecimiento de este segmento del mercado y mejorar la alimentación de la población de los países en desarrollo y desarrollados (Martínez, 2002). Según Martínez (2002), el mayor desarrollo tecnológico en el procesamiento industrial de la

1 Facultad de Ciencias Agrarias y Forestales, Departamento de Ciencias Agrarias. Universidad Católica del Maule. Carmen 684, Casilla 7-D, Curicó. CHILE. 2007. nloyola@ucm.cl 
papa, utilizando como indicadores la generación de patentes, ha sido el procesamiento de tubérculos para la elaboración de papas fritas, secado y obtención de almidón. Lo expuesto transcurrió entre los años 1970 y 1972, alcanzando su máximo nivel con una producción de 550 patentes anuales promedio, llegando a niveles mínimos en la década de los 90 con 190 patentes anuales. Los principales mercados que han desarrollado estas tecnologías son EE.UU., Alemania, Reino Unido, Suiza, Japón y otros (Martínez, 2002).

La papa es el cuarto producto en importancia alimenticia después del maíz, trigo y arroz. La producción mundial es de 300.000.000 de ton, provenientes de un área sembrada de 18.000 .000 de ha, con una productividad promedio de 16 ton/ha (Campos et al., 2000; Lachman et al., 2001; Ezeta, 2002). En América Latina se producen 8 millones de ton de papas anualmente (Dilmer, 2000). El rendimiento de almidón por ha. es de 2,72 ton. En América del Sur se siembran apenas 600.000 ha y se logra una productividad media de ton/ha. Esto equivale a un aporte de tan sólo $4 \%$ de la oferta mundial. Es paradojal el hecho de que siendo este continente americano el lugar físico de origen de esta solanácea, y por ende su nicho ecofisiológico, haya sido ampliamente superada por otras regiones productoras en el mundo (Campos et al., 2000). En Chile, el cultivo de la papa constituye uno de los principales rubros agrícolas, ya sea desde el punto de vista social, económico y por su aporte nutricional en la alimentación humana (Geldres, 1990; Santos, 1998; Acuña, 2004). La superficie sembrada en los últimos 30 años en Chile ha sido en promedio de 62.000 ha, con fluctuaciones principalmente por el factor precio. Por otro lado, los rendimientos han tenido una mejora, ya que de 10 ton ha $^{-1}$ en la temporada de 1978 a 1979 han aumentado a 22 ton. ha $^{-1}$ en la temporada 2005 a 2006 (ODEPA, 2007). El principal uso es en la alimentación humana, mediante el consumo fresco representado con un $71 \%$, el uso industrial representado por un $15 \%$, el cual se compone por papas fritas en hojuela y bastones, puré y almidón. Cabe mencionar que también el porcentaje de pérdida es bastante elevado, representando un $14 \%$. La tendencia actual es disminuir la brecha entre el consumo de tubérculos frescos e industrial y disminuir el porcentaje de pérdidas (Santos et al., 2001).

La industria de la papa exige un tubérculo de calidad, esto sí dependiendo del objetivo de procesamiento. Por esto, tubérculos destinados a papas fritas deben ser bajos en azúcares reductores y altos en materia seca, de esta forma se evitan colores y sabores desagradables y se economiza aceite al freír, además, deberán tener una forma alargada y un tamaño adecuado. Si el objetivo es la extracción de almidón, estas deben tener un alto contenido de materia seca, ya que existe una alta correlación entre el contenido de materia seca y almidón (Gomes y Wong, 1998), además de un buen contenido de ácido fosfórico ya que este es el responsable de dar la viscosidad a este polisacárido (Artacho, 1975), más aún cuando este se usa como ingrediente gelatinizante de otros productos, como es el caso de algunas jaleas a partir de almidón de papas (Andrade, 1997; García et al., 2002). Cabe mencionar que la calidad de las papas se refiere tanto a parámetros externos e internos del tubérculo. Los primeros hacen mención a la forma, tamaño, “ojos superficiales”, daños mecánicos y de plagas; en cambio, los segundos están referidos a la composición química del tubérculo, ya sean azúcares totales, reductores, almidón, proteínas, entre otros (González, 2000; García, 2002).

Actualmente existe una tendencia hacia una alimentación más saludable, de ahí que la agricultura orgánica ha puesto mayor énfasis para satisfacer estos segmentos del mercado que se han producido. Por esta razón, y sumado al desarrollo tecnológico que ha sufrido este rubro, nace la inquietud de conocer si esta forma de cultivo es capaz de entregar un tubérculo con calidad industrial. Para apoyar lo mencionado anteriormente se planteó como objetivo general: evaluar el contenido de almidón en papas (Solanum tuberosum sp. Tuberosum cv. Desirée), cultivadas en forma orgánica y convencional.

Como objetivos específicos se indican: cuantificar el contenido de almidón en ambas formas de cultivo. Cuantificar el contenido de azúcares totales y reductores en ambas formas de cultivo. Cuantificar el contenido de proteínas en ambas formas de cultivo. Evaluar la aceptabilidad sensorial de papas derivada de ambas formas de cultivo.

\section{MATERIALES Y MÉTODOS}

El presente trabajo de investigación ha contado con el apoyo de la Dirección de Investigación y Perfeccionamiento de la Universidad Católica del 
Maule, dado que correspondió a un proyecto interno número 811-07, adjudicado el año 2006.

El ensayo se realizó en el Campus San Isidro, perteneciente a la Universidad Católica del Maule, ubicado a $5,5 \mathrm{~km}$. al este de la ciudad de Curicó. El Campus cuenta con 16 ha, de las cuales 10 son certificadas orgánicas por la empresa BCS Chile Ltda. con oficina en la ciudad de Chillán. La zona tiene una topografía plana, con un suelo perteneciente a la serie macarena (CIREN CORFO, 1997), el clima es templado, con una máxima en enero de $27^{\circ} \mathrm{C}$ y una mínima de $4,1^{\circ} \mathrm{C}$ en julio, con un período libre de heladas de 219 días y un período de 11 heladas anuales, con precipitaciones medias de $859 \mathrm{~mm}$ (Santibáñez, 1993).

Para la siembra se utilizaron tubérculos de papas (Solanum tuberosum sp, tuberosum) del cultivar Desirée, las cuales fueron conseguidas en el mercado local de semillas de papas certificadas provenientes del sur del país, sector de Los Muermos.

Antes de las preparaciones del suelo se realizó un análisis del mismo, tanto en el sector orgánico como de cultivo convencional del predio; ello se hizo en el Laboratorio Enológico de Certificación y Control de Calidad de la Universidad Católica del Maule, ubicado en Longitudinal Sur km 205, camino a la comuna de Molina, Región del Maule. Se solicitaron a dicho laboratorio los contenidos de macro y micronutrientes, materia orgánica, $\mathrm{pH}$ y conductividad eléctrica.

Las preparaciones y laboreos de suelo comenzaron a mediados de septiembre para sembrar el 15 de octubre del 2006. La siembra se realizó en forma manual con una densidad de plantas de 53.320 plantas/ha $(0,25 \mathrm{~m} \times 0,75 \mathrm{~m})$, siendo la dirección de los surcos de este-oeste (Huber et al., 1998), no aplicándose algún tipo de fertilizante y pesticida en ningún momento del desarrollo del cultivo en ambos terrenos. Una vez que se estableció el cultivo, se realizaron las labores normales de este, tales como: control de malezas, aporcas, riegos y otros.

La cosecha de ambas formas de cultivo se realizó el 10 de febrero del 2007, esta fue en forma manual y se cosecharon durante un día. Se utilizaron como índice de madurez fisiológica el secado del vástago y la firmeza de la piel.

Posteriormente, los tubérculos de papas fueron almacenados, utilizando una "troja" como contenedor durante 15 días a una temperatura de $15^{\circ} \mathrm{C}$ y con una humedad relativa de $85 \%$, en un cuarto oscuro. La construcción de la "troja" fue con listones de madera secos de 2 x 1 pulgadas, cuyas dimensiones fueron de $2 \mathrm{~m}$ de largo por 0,6 $\mathrm{m}$ de ancho y por $1 \mathrm{~m}$ alto y cuya superficie comenzaba a $0,2 \mathrm{~m}$. La distancia entre cada listón fue de 1 pulgada; cada "troja" constaba con un cañón de madera de $0,2 \mathrm{~m} \times 0,2 \mathrm{~m} \times 1 \mathrm{~m}$, el cual se colocó al centro de la misma en posición vertical con el objeto de favorecer la ventilación de los tubérculos (Santander, 1983; Guglielmetti, 1982).

\section{ANÁLISIS QUÍMICO}

Se cuantificó el contenido de materia seca, almidón, proteína, azúcares totales y azúcares reductores. El primer análisis se realizó a los 15 días poscosecha, una vez terminado el proceso del curado; el segundo y tercero se efectuaron a los 45 y 75 días, respectivamente.

El método usado para medir el contenido de almidón, azúcares totales y reductores fue el de Muson y Walter y para determinar el contenido de proteínas se usó el método de Kejldahl. Para determinar el contenido de materia seca se utilizó el método de materia seca absoluta.

\section{ANÁLISIS ESTADÍSTICO}

El análisis estadístico utilizado, para discernir diferencias entre ambas formas de cultivo, fue un diseño completamente al azar, utilizando análisis de varianzas para ver las diferencias con un $95 \%$ de exigencia.

El cultivo convencional fue el tratamiento testigo $\left(\mathrm{T}_{0}\right)$ y el cultivo de papas en forma orgánica el tratamiento a comparar $\left(\mathrm{T}_{1}\right)$, realizándose en cada fecha de evaluación tres repeticiones, siendo $2 \mathrm{k}$ de papas la unidad experimental.

\section{EVALUACIÓN SENSORIAL}

Se realizaron dos evaluaciones sensoriales, cada una de ellas con tres repeticiones, de los tubérculos cocinados mediante fritura a los 30 y 75 días poscosecha, evaluando, mediante la participación de 13 panelistas entrenados, tanto los atributos organolépticos como la aceptación de las muestras analizadas. Se midieron atributos organolépticos como color, sabor y textura mediante una cartilla de evaluación sensorial no estructurada, en la cual cada 
atributo fue evaluado por los panelistas, quien marcó su impresión en una línea de $13 \mathrm{~cm}$ con una raya vertical; posteriormente esa evaluación se traspasó a valores numéricos (Figura 1). La medición del grado de aceptación de las muestras fue realizada mediante una cartilla estructurada, donde el panelista colocaba una nota de 1 a 9 , según su apreciación de aquellas desde una menor a mayor aceptabilidad, respectivamente (Figura 2). Para identificar qué muestra(s) fue(ron) mejor evaluada(s) se utilizaron gráficos radiales, expresando en las zonas en donde coinciden todos los atributos y la mayor aceptación, de parte de los panelistas, como aquella en que hay una zona achurada común.

Usted ha sido seleccionado para participar en un análisis sensorial de un producto nuevo, próximo a salir en el mercado. Se le pide que marque con una línea vertical los atributos que a continuación se describen, desde menos intenso a más intenso, de izquierda a derecha, respectivamente.

\begin{tabular}{|c|c|}
\hline Muestra: & Fecha: \\
\hline \multicolumn{2}{|l|}{ Panelista: } \\
\hline \multicolumn{2}{|l|}{ COLOR } \\
\hline Claro & Oscuro \\
\hline \multicolumn{2}{|l|}{ TEXTURA } \\
\hline Harinosa & Crocante \\
\hline SABOR & \\
\hline
\end{tabular}

Observaciones:

Figura 1. Cartilla de evaluación sensorial.

Fuente: Adaptada de Stone and Sidel (1993).

Usted ha sido seleccionado para participar en un análisis sensorial de un producto nuevo, próximo a salir en el mercado. Se le pide su opinión respecto del grado de aceptabilidad que significó este producto. Encierre en un círculo, de 9 a 1, su opinión según el grado de satisfacción, de mayor a menor, respectivamente.

\begin{tabular}{lll}
\hline Muestra: & Fecha: \\
Panelista: & 9 \\
Excelente & 8 \\
Buena & 7 \\
Aceptable & 6 \\
Más que regular & 5 \\
Indiferente & 4 \\
Regular & 3 \\
Menos regular & 2 \\
Mala & 1 \\
Inaceptable & \\
\hline
\end{tabular}

Figura 2. Cartilla de aceptabilidad.

Fuente: Adaptada de Stone and Sidel (1993). 


\section{MANTECA VEGETAL}

Para freír las papas se utilizó manteca vegetal de la marca Ritz, importada por Lesaffre Chile, S.A., y cuyos ingredientes fueron: aceite refinado de palmas y antioxidantes.

\section{TIEMPO FRITURA}

El tiempo de fritura fue de 9 minutos para todas las muestras evaluadas.

\section{SALA DE CATA}

Esta sala constó de 13 cabinas individuales de color blanco con mesones y luces de igual color. La sala de cata cumplía con los requisitos de la norma UNE 87-004-79, la cual especifica que se deben evitar condiciones ambientales que interfieran en la respuesta de los jueces, tales como olores, ruidos y conversaciones entre ellos, además, la norma establece que dicha evaluación debe realizarse en cabinas individuales e independientes, con paneles laterales y ventanillas para recibir las muestras, evitando así la comunicación entre y con los panelistas, otorgándoles comodidad y privacidad a los mismos. Además, la sala de cata tuvo una adecuada luminosidad, tanto ambiental como individual, y una temperatura de $25^{\circ} \mathrm{C}$.

\section{PANEL DE CATADORES}

Para la realización del perfil sensorial de las papas fritas provenientes de los tubérculos del

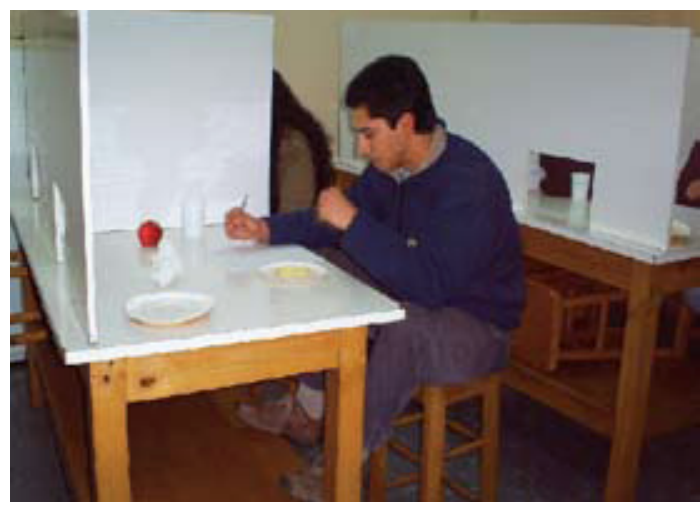

Figura 3. Momento de la evaluación sensorial. Paneles con divisiones y ventanillas.

Fuente: propia. ensayo se contó con un panel de jueces compuesto por 13 personas seleccionadas y entrenadas. En la Figura 3 se muestra el momento en que los panelistas realizaban la evaluación sensorial.

\section{OTROS MATERIALES DURANTE LA EVALUACIÓN SENSORIAL}

Al momento de realizar la evaluación sensorial cada panelista debió contar en su cabina con la muestra de papas fritas recién elaboradas, en un platillo de cartón blanco, un platillo de cartón blanco con una manzana, un vaso plástico blanco con agua, lápiz pasta azul, un resumidero, servilletas y dos cartillas de respuesta con el respectivo número de la muestra.

En la evaluación sensorial las unidades experimentales fueron muestras de $20 \mathrm{~g}$ de bastones de papas fritas. El análisis estadístico fue en bloques completamente al azar (BCA), utilizando gráficos radiales para ver dónde los panelistas concordaron en los tres atributos evaluados y el grado de aceptabilidad de las muestras.

\section{RESULTADOS Y DISCUSIÓN}

\section{ANÁLISIS QUÍMICOS}

Se evaluó en tubérculos de papas producidos en forma convencional y orgánica el contenido de materia seca, almidón, proteínas, azúcares totales y azúcares reductores, a los 15, 45 y 75 días después de cosechados (Cuadro 1).

El contenido de materia seca analizado en los tubérculos del ensayo no exhibió diferencias estadísticamente significativas $(\mathrm{p}<0,05)$ para ambas formas de cultivo. En general, el cultivo de tipo convencional de papas $\left(\mathrm{T}_{0}\right)$ dio por resultado contenidos levemente superiores de materia seca respecto del tratamiento de cultivo orgánico $\left(\mathrm{T}_{1}\right)$. Esta leve diferencia puede ser debido a que, según Storey y Davies (1992), el cloruro de potasio existente en algunos suelos reduciría el contenido de materia seca esperado en tubérculos cultivados en aquellos. Lo anterior probablemente pudo haber ocurrido en los tubérculos cultivados mediante el tratamiento orgánico $\left(\mathrm{T}_{1}\right)$, ello considerando que el análisis de suelo realizado previo al inicio del presente ensayo arrojó 278 ppm de potasio, en comparación al análisis de suelo del sector donde se realizó el tratamiento 
Cuadro 1

Análisis químico de tubérculos de papas producidos en forma convencional y orgánica, en porcentaje (\%)

\begin{tabular}{|l|c|c|c|c|c|c|c|c|}
\hline \multirow{2}{*}{ Componente } & \multicolumn{4}{|c|}{ Cultivo convencional } & \multicolumn{4}{c|}{ Cultivo orgánico } \\
\cline { 2 - 9 } & $\mathbf{1 5}$ & $\mathbf{4 5}$ & $\mathbf{7 5}$ & Promedio & $\mathbf{1 5}$ & $\mathbf{4 5}$ & $\mathbf{7 5}$ & Promedio \\
\hline Materia seca & $25,00^{\mathrm{a}}$ & $22,76^{\mathrm{a}}$ & $25,30^{\mathrm{a}}$ & $24,35^{\mathrm{a}}$ & $22,48^{\mathrm{a}}$ & $23,01^{\mathrm{a}}$ & $24,00^{\mathrm{a}}$ & $23,16^{\mathrm{a}}$ \\
\hline Almidón & $13,79^{\mathrm{a}}$ & $15,92^{\mathrm{a}}$ & $13,67^{\mathrm{a}}$ & $14,46^{\mathrm{a}}$ & $12,18^{\mathrm{a}}$ & $15,89^{\mathrm{a}}$ & $12,67^{\mathrm{a}}$ & $13,58^{\mathrm{a}}$ \\
\hline Proteínas & $2,67^{\mathrm{a}}$ & $2,92^{\mathrm{a}}$ & $2,34^{\mathrm{a}}$ & $2,64^{\mathrm{a}}$ & $2,81^{\mathrm{a}}$ & $2,99^{\mathrm{a}}$ & $2,69^{\mathrm{a}}$ & $2,83^{\mathrm{a}}$ \\
\hline Azúcares totales & $0,20^{\mathrm{a}}$ & $0,19^{\mathrm{a}}$ & $0,21^{\mathrm{a}}$ & $0,20^{\mathrm{a}}$ & $0,18^{\mathrm{a}}$ & $0,18^{\mathrm{a}}$ & $0,21^{\mathrm{a}}$ & $0,19^{\mathrm{a}}$ \\
\hline Azúcares reductores & $0,13^{\mathrm{a}}$ & $0,14^{\mathrm{a}}$ & $0,13^{\mathrm{a}}$ & $0,13^{\mathrm{a}}$ & $0,10^{\mathrm{a}}$ & $0,11^{\mathrm{a}}$ & $0,11^{\mathrm{a}}$ & $0,11^{\mathrm{a}}$ \\
\hline
\end{tabular}

Fuente: Propia, 2007.

Valores promedios seguidos por letras iguales en dirección horizontal, no difieren estadísticamente con $\mathrm{p}<0,05$.

convencional $\left(\mathrm{T}_{1}\right)$, el que dio valores superiores a 120 ppm de potasio. Según Hans (1998), el cloro es un elemento que se puede encontrar en distintos tipos de suelos y en niveles muy variados, desde 0,5 ppm a $6.000 \mathrm{ppm}$, por lo que es muy probable que se haya formado cloruro de potasio con el potasio existente en la solución del suelo, bajo ambas formas de cultivo, particularmente en aquel con el tratamiento $\mathrm{T}_{1}$, afectando negativamente sobre el contenido de materia seca en los tubérculos cultivados en forma orgánica. Además, según estos autores, fertilizaciones de nitrógeno y potasio en exceso reducirían el contenido de materia seca en tubérculos cultivados; estos dos macronutrientes en el análisis de suelo del sector de cultivo orgánico del ensayo arrojaron valores mayores. Altas temperaturas ambientales, superiores a $21{ }^{\circ} \mathrm{C}$, retrasan la acumulación de carbohidratos en los tubérculos, particularmente altas temperaturas durante la noche, lo que sumado a una baja retención de humedad en los suelos, como ocurriría en aquellos de sistemas de cultivo convencional, producirían tubérculos con contenidos levemente mayores de materia seca. Lo anterior coincide con las condiciones del ensayo, ya que a pesar de no ser cuantificada la capacidad de retención de humedad, sí se apreció que el suelo donde se desarrolló el cultivo convencional era demasiado secante en relación al suelo de la alternativa de cultivo orgánico. Desde el punto de vista óptimo para el desarrollo del cultivo de papa, temperaturas de $15^{\circ} \mathrm{C}$ a $25^{\circ} \mathrm{C}$ son las más adecuadas en términos de fijación de $\mathrm{CO}_{2}$, necesaria para una fotosíntesis más eficiente, translocación de fotosintatos y conversión en materia seca (Fuentealba, 2001).

El contenido de almidón obtenido en los tubérculos sometidos a ambos tratamientos no mostró diferencias estadísticamente significativas en ambos cultivos $(\mathrm{p}<0,05)$. En general, el cultivo convencional de papas $\left(\mathrm{T}_{0}\right)$ obtuvo un contenido superior de almidón en los tubérculos, en relación a lo ocurrido al tratamiento $\left(\mathrm{T}_{1}\right)$ orgánico. Lo anterior concuerda con Rodríguez et al. (2000), quienes evaluaron la composición química y nutricional de tubérculos durante cuatro temporadas, obtenidos a partir de cultivos orgánico y convencional, y no encontraron diferencias significativas, a pesar de que el cultivo convencional alcanzó mayores contenidos de almidón. Por otro lado, autores como Storey y Davies (1992) y Hans (1998) señalan que el efecto de la sinergia del nitrógeno, potasio y cloruro de potasio tiene un efecto negativo en el contenido de almidón, lo que pudo haber atentado en contra de la cantidad de almidón factible de acumular en los tubérculos, particularmente al haber sido cultivado en forma orgánica $\left(\mathrm{T}_{1}\right)$.

Según Cáceres (1991), existe una correlación mayor a 0,95 entre el contenido de materia seca y el contenido de almidón, lo que explicaría la diferencia a favor de los tubérculos cultivados según el tratamiento convencional $\left(\mathrm{T}_{0}\right)\left(\mathrm{T}_{1}\right)$, respecto del cultivo orgánico $\left(\mathrm{T}_{1}\right)$.

En general, los contenidos de almidón en ambas formas de cultivo del ensayo están por debajo de los valores normales obtenidos en tubérculos de 
este cultivar, ya que, según Cáceres (1991), los rangos normales de almidón varían entre un $15,56 \%$ y $17,76 \%$, y contenidos menores no la harían recomendable para la extracción de almidón.

En el presente estudio, tubérculos provenientes de ambas formas de cultivo fueron cosechados en la misma fecha, 10 de febrero del 2007, siendo el índice de madurez fisiológica la muerte del vástago, de un $80 \%$ en el tratamiento orgánico $\left(\mathrm{T}_{1}\right)$ contra un $95 \%$ del cultivo convencional $\left(\mathrm{T}_{0}\right)$. Con respecto a lo anterior, existe discrepancia en relación al índice de madurez fisiológica y su valor porcentual dado que el máximo contenido de materia seca de los tubérculos se alcanzaría con un índice de madurez de $70 \%$ de vástago deshidratado; sin embargo, se amplía este porcentaje a un $80 \%$ de vástago deshidratado, todos ellos citados por Cáceres (1991).

El contenido de proteínas no difirió estadísticamente en ambas formas de cultivo; sin embargo, el contenido de proteínas fue levemente mayor en el cultivo orgánico sobre el cultivo convencional. Rodríguez et al., (2000) no encontraron diferencias significativas al comparar ambas formas de cultivo, durante cuatro temporadas, respecto del contenido de proteínas de los tubérculos, lo que también se obtuvo en el presente estudio. Según Hans (1998), mayores niveles de nitrógeno en el suelo aumentarían el contenido de proteínas de los tubérculos, lo que se ratificó en este ensayo, dado que el nitrógeno disponible del suelo, según el análisis realizado inicialmente, fue mayor en el tratamiento orgánico $\left(\mathrm{T}_{1}\right)$ y también el contenido de proteínas de los tubérculos.

En el contenido de azúcares totales no se encontraron diferencias estadísticamente significativas en los tubérculos del estudio, en ninguna de las fechas evaluadas y en ambas formas de cultivo, tratamientos $\left(\mathrm{T}_{0}\right)$ y $\left(\mathrm{T}_{1}\right)$, a pesar de que el cultivo convencional produjo tubérculos con valores levemente superiores sobre el cultivo orgánico.

En el contenido de azúcares reductores tampoco se encontraron diferencias estadísticamente significativas en ambas formas de cultivo, tratamientos $\left(\mathrm{T}_{0}\right)$ y $\left(\mathrm{T}_{1}\right)$, no obstante el cultivo convencional produjo tubérculos con valores mayores, respecto del cultivo orgánico. Rodríguez et al. (2000) y posteriormente Geigenberger (2003) al comparar ambas formas de cultivo de papas tanto orgánica como convencional, durante cuatro temporadas, tampoco encontraron diferencias significativas respecto del contenido de azúcares reductores en los tubérculos, pero, al igual que en el presente ensayo, el cultivo convencional produjo papas con valores mayores que el orgánico.

\section{EVALUACIÓN SENSORIAL}

La opinión de los jueces, quienes evaluaron las papas fritas elaboradas a partir de tubérculos provenientes de dos tratamientos, convencional y orgánico $\left(\mathrm{T}_{0}\right)$ y $\left(\mathrm{T}_{1}\right)$, se expresó mediante la identificación de los atributos sensoriales y de aceptabilidad de las muestras evaluadas (Cuadro 2), (Figura 4), (Cuadro 3) y (Figura 5).

\section{Cuadro 2}

Promedio de evaluaciones sensoriales, medición organoléptica de la intensidad de atributos de papas fritas, con tubérculos producidos en un cultivo convencional

\begin{tabular}{|c|c|c|c|c|}
\hline $\mathbf{N}^{\mathbf{o}}$ de muestra & Color & Textura & Sabor & Aceptación \\
\hline 1 & 4,0 & 6,5 & 6,0 & 7,3 \\
\hline 2 & 5,7 & 5,7 & 6,5 & 7,5 \\
\hline 3 & 6,6 & 5,7 & 5,5 & 7,1 \\
\hline
\end{tabular}

Fuente: Propia, 2007.

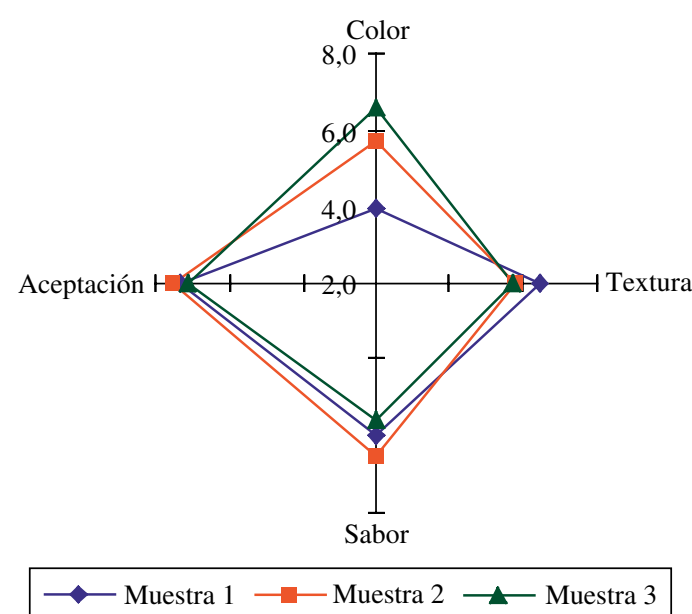

Figura 4. Promedio de evaluaciones sensoriales por atributos en papas fritas provenientes de tubérculos producidos en un cultivo convencional.

Fuente: Propia, 2007. 
Al observar el Cuadro 2 y la Figura 4 se puede decir que los panelistas identificaron atributos sensoriales en papas fritas en diferente intensidad, todas provenientes de tubérculos cultivados en forma convencional $\left(\mathrm{T}_{0}\right)$. Las muestras en general fueron percibidas por los panelistas como de colores claros, sabores levemente insípidos y de textura media o muy poca harinosa y se tradujo en un grado de aceptación considerado como aceptable. Los atributos mejor identificados por los panelistas fueron el color y la textura, siendo la muestra 1 la que mejor los reflejó, pero en general todas tuvieron un grado de aceptabilidad similar y no resultó ser muy alto. Es importante señalar que la industria de papas fritas prefiere aquellas en que, luego de freírlas, los bastones permanecen de colores claros, lo que se fundamenta en el contenido de almidón, el cual resulta inversamente proporcional al contenido de azúcares reductores. Colores claros son bien juzgados por los consumidores, tales como blanco-amarillento y amarillo oro, considerados aceptables y deseables, respectivamente (Dilmer, 2000).

Con respecto a la textura, fue evaluada con una puntuación de 6,5 , siendo un valor intermedio en la escala utilizada de 0 a 13, implicando una textura media y aceptada para utilizar los tubérculos en agroindustria de papas fritas.

$\mathrm{El}$ atributo sabor, si bien fue evaluado por los panelistas como levemente más bajo que la muestra 2 , de igual modo estuvo dentro del rango de insípido o de tipo neutro, lo cual se condice con lo expuesto para el cultivar Desirée de parte de los creadores de este (INIA, 2007).

En el caso del cultivo según la forma orgánica $\left(\mathrm{T}_{1}\right)$, los resultados promedios por atributo y por muestra se exhiben en el Cuadro 3 y en la Figura 5, pudiéndose diferenciar cuál de las tres muestras presentó una mejor identificación de sus atributos y con mayor grado de aceptación.

\section{Cuadro 3}

Promedio de evaluaciones sensoriales, medición organoléptica de la intensidad de atributos de papas fritas, con tubérculos producidos en un cultivo orgánico

\begin{tabular}{|c|c|c|c|c|}
\hline Muestra & Color & Textura & Sabor & Aceptación \\
\hline 1 & 4,8 & 6,3 & 6,0 & 7,1 \\
\hline 2 & 4,4 & 5,1 & 5,3 & 6,7 \\
\hline 3 & 4,6 & 5,4 & 7,0 & 7,0 \\
\hline
\end{tabular}

Fuente: Propia, 2007.

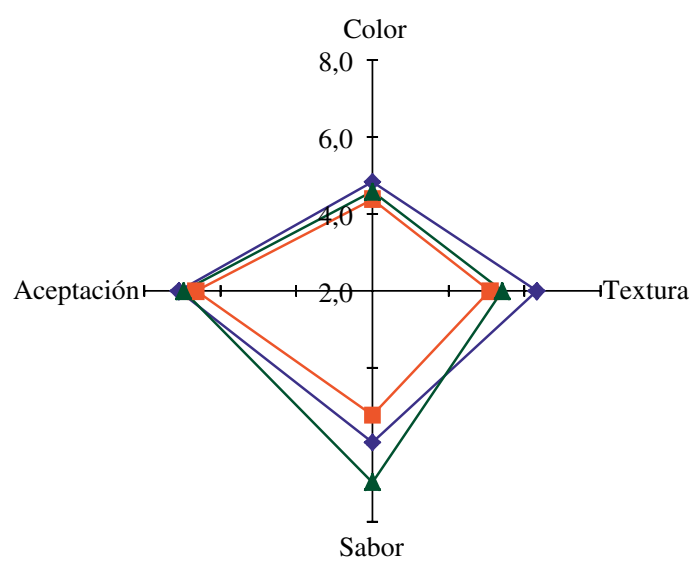

$\multimap$ Muestra $1 \multimap-$ Muestra $2 \multimap$ Muestra 3

Figura 5. Promedio de evaluaciones sensoriales por atributos en papas fritas, provenientes de tubérculos producidos en un cultivo orgánico.

Fuente: Propia, 2007.

Al observar el Cuadro 3 y la Figura 5 se puede decir que los panelistas identificaron los atributos sensoriales en las muestras de papas fritas todas provenientes de tubérculos cultivados en forma orgánica $\left(T_{1}\right)$. Las muestras en general fueron percibidas por los panelistas como de colores claros, sabores menos insípidos y de textura media o muy poca harinosa, lo que derivó en un grado de aceptación considerado como aceptable. Los atributos mejor identificados por los panelistas fueron el color y el sabor, siendo la muestra 3 la que mejor los caracterizó, pero en general todas tuvieron un grado de aceptabilidad similar, no siendo muy alta. El atributo color, de la muestra 3, fue evaluado por el consenso de los panelistas con una puntuación de 4,6 , lo cual se acerca más hacia el extremo del sector claro, siendo esta una característica bien considerada por los consumidores y el sector agroindustrial.

El atributo textura de la muestra 3 fue evaluado con una puntuación de 5,4, siendo este un valor más cercano al extremo de textura harinosa, lo que se explicaría fundamentalmente por los niveles bajos de materia seca de los tubérculos cultivados bajo la forma orgánica y en particular reflejado en la muestra 3. Si bien la diferencia porcentual de materia seca requerida por la agroindustria es levemente mayor (25\%) a la obtenida en el presente ensayo con la forma de cultivo orgánico $(23,16 \%)$, lo cierto es que la diferencia es mínima y por ende los tubérculos obtenidos según el tratamiento $\left(\mathrm{T}_{1}\right)$ serían aptos para 
elaborar papas fritas. El atributo sabor en la muestra 3 fue evaluado con una puntuación de 7,0 por los panelistas, lo cual está levemente desplazado del centro de la escala no estructurada utilizada en la percepción de atributos, e indicando menos tendencia hacia el extremo insípido, corroborando lo señalado para las características atribuidas a los tubérculos del cultivar Desirée, que los califican como papas de sabor neutro. La aceptabilidad de las papas fritas provenientes de tubérculos cultivados bajo la forma orgánica $\left(\mathrm{T}_{1}\right)$ fue de 7,0, siendo considerada aceptable.

\section{COMPARACIÓN DE AMBOS CULTIVOS}

Es posible realizar un análisis de ambas formas de cultivos: convencional $\left(\mathrm{T}_{0}\right)$ y orgánica $\left(\mathrm{T}_{1}\right)$, el cual se exhibe en el Cuadro 4 y en la Figura 6.

\section{Cuadro 4}

Promedio de evaluaciones sensoriales, medición organoléptica de la intensidad de atributos de papas fritas, provenientes de tubérculos producidos en cultivos convencional y orgánico

\begin{tabular}{|l|c|c|c|c|}
\hline Tipo de cultivo & Color & Textura & Sabor & Aceptación \\
\hline Convencional $\left(\mathrm{T}_{0}\right)$ & 5,4 & 6,0 & 6,0 & 7,3 \\
\hline Orgánico $\left(\mathrm{T}_{1}\right)$ & 4,6 & 5,6 & 6,1 & 6,9 \\
\hline
\end{tabular}

Fuente: Propia, 2007.

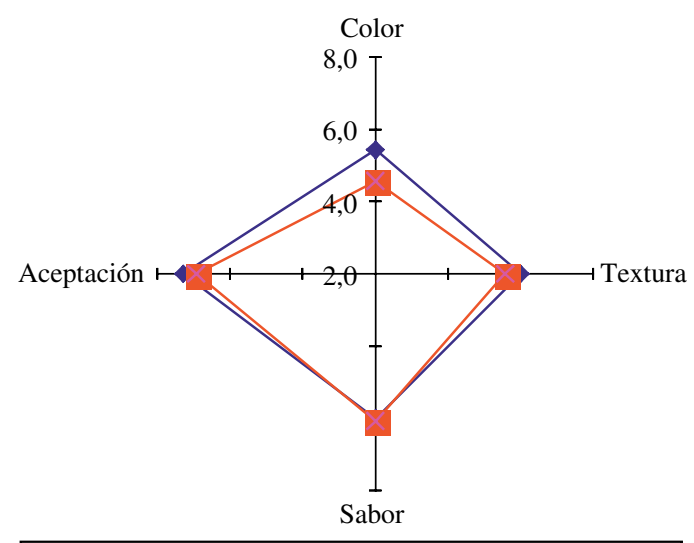

$\neg$ Cultivo convencional $\longrightarrow$ Cultivo orgánico

Figura 6. Promedio de evaluaciones sensoriales por atributos en papas fritas, provenientes de tubérculos producidos en cultivos convencional $\left(\mathrm{T}_{0}\right)$ y orgánico $\left(\mathrm{T}_{1}\right)$.

Fuente: Propia, 2007.
Color: Este atributo sensorial, analizado en las papas fritas por los panelistas, fue mejor evaluado particularmente de aquellas provenientes del tratamiento $\left(\mathrm{T}_{1}\right)$, obtenidas de tubérculos cultivados de forma orgánica, dado que los bastones se apreciaron de colores más claros que aquellos del tratamiento de cultivo convencional $\left(\mathrm{T}_{0}\right)$. Lo anterior resulta ser un factor relevante en la industria de productos tratados a temperaturas altas, causando caramelización de los azúcares componentes. En este sentido, hay evidencias médicas que permiten considerar a los productos caramelizados, debido a los azúcares reductores, como responsables de problemas como sobrepeso, diabetes, entre otros. El análisis químico ya expuesto previamente en este estudio, y según el cual la forma de cultivo orgánica $\left(\mathrm{T}_{1}\right)$ incidió en un menor contenido de azúcares reductores, fue apoyado por una mayor identificación y aceptación de bastones de papas fritas de colores más claros por parte de los panelistas. Además de la forma de cultivo y temperatura de almacenamiento de los tubérculos cosechados, habría otras causales en el incremento de los azúcares reductores e indirectamente en el color de aquellos cuando son sometidos a freído. En este sentido, Loyola et al. (1999) evaluaron papas fritas de la variedad Ranger Russet, almacenadas bajo tres tipos de atmósfera modificada (AR: $21 \% \mathrm{O}_{2}$ y 0,003\% $\mathrm{CO}_{2}$; $\mathrm{AC}: 12 \%$ $\mathrm{O}_{2}$ y $5 \% \mathrm{CO}_{2}$; $\mathrm{AC}: 6 \% \mathrm{O}_{2}$ y $5 \% \mathrm{CO}_{2}$ ), encontrando que aquellas provenientes de tubérculos almacenados en las condiciones de AC eran peor evaluadas por los panelistas, no sólo en el atributo color, sino también sabor. Estudios de Dilmer (2000) señalan que la modificación de las concentraciones de $\mathrm{CO}_{2}$ de $0,06 \%$ a $3,2 \%$ en una bodega para producir aumentos en la cantidad de azúcares reductores de los tubérculos almacenados, resultaría en papas fritas de tonos oscuros. Sin embargo, este mismo autor también ha señalado que colores de tubérculos como blanco amarillento y amarillo oro son aceptables y deseables por los consumidores y la agroindustria de papas fritas, respectivamente.

Textura. Este atributo sensorial fue levemente mejor evaluado en papas fritas provenientes de tubérculos cultivados en forma convencional $\left(\mathrm{T}_{0}\right)$, ya que obtuvo un valor de 6 contra 5,6 de aquellas provenientes de tubérculos cultivados en forma orgánica $\left(\mathrm{T}_{1}\right)$. Sin embargo, ambos valores están más cercanos al extremo harinoso que al crocante, en la escala no estructurada utilizada en la cartilla 
de evaluación sensorial, siendo esto explicado por el mayor contenido de materia seca que obtuvieron los tubérculos cultivados en forma convencional $\left(\mathrm{T}_{0}\right)$, de acuerdo al análisis químico realizado. El contenido de materia seca promedio de los tubérculos fue de $24,4 \%$ y $23,16 \%$ en la forma de cultivo convencional y orgánico, respectivamente. De acuerdo a González (2000), ambos tubérculos provenientes de las dos formas de cultivo de este ensayo $\left(\mathrm{T}_{0}\right)$ y $\left(\mathrm{T}_{1}\right)$ cumplirían con los requisitos de la agroindustria para su uso como papas fritas ya que según el autor sobre un $20 \%$ de materia seca resulta ideal para dicho uso. Dilmer (2000), por el contrario, señala que el contenido ideal de materia seca de tubérculos destinados a papas fritas debe ser como mínimo de un $25 \%$. Otro factor que también influye en la textura de papas fritas es el contenido de almidón de los tubérculos en este sentido contenidos altos otorgarían buena textura del producto cocido y un menor grado de harinosidad (Loyola et al., 1999). De acuerdo a lo antes mencionado, también explicaría la mejor evaluación de papas fritas provenientes de los tubérculos producidos en forma convencional $\left(\mathrm{T}_{0}\right)$, siendo apoyado con la determinación química del contenido de almidón, la cual fue de 14,46\% para aquel versus un $13,58 \%$ de almidón en tubérculos del cultivo orgánico $\left(\mathrm{T}_{1}\right)$.

El término textura involucra la estructura física de los materiales y la sensación táctil en la boca, lo que en papas ha sido relacionada con el contenido de almidón, contenido de celulosa de las paredes celulares, y constituyentes de la lámina media de las células involucradas en los tejidos analizados. La textura de los tejidos analizados, manifestando harinosidad, crocancia y firmeza, está positivamente relacionada con el contenido de materia seca, almidón, tamaño de los gránulos de almidón, gravedad específica y sólidos insolubles en alcohol que posean los tubérculos a emplear en la agroindustria (Loyola et al., 1999).

Sabor. Este atributo sensorial fue evaluado como igual por los panelistas, luego de probar papas fritas provenientes de tubérculos de ambas formas de cultivo convencional $\left(\mathrm{T}_{0}\right)$ y cultivo orgánico $\left(\mathrm{T}_{1}\right)$; sin embargo, ambos están evaluados con valores hacia el extremo insípido. Aparentemente, serían la textura sobre el color y sabor, dentro de ciertos rangos de tolerancia aceptados por la industria de papas fritas, los atributos sensoriales que más influirían en la identificación y aceptación de aquellas por los panelistas y que en este caso correspondió al tratamiento de cultivo convencional de papas cv. Desirée $\left(\mathrm{T}_{0}\right)$. Loyola et al. (1999) en su estudio bajo las condiciones que se mencionaron anteriormente señalaron que a medida que se bajan las concentraciones de $\mathrm{O}_{2}$ en el almacenamiento, los tubérculos son evaluados como de peor sabor por los panelistas, esto porque los patrones de respiración de los tubérculos se ven afectados y aumentan las concentraciones de azúcares reductores. En este sentido, se plantea la posibilidad de retomar la evaluación sensorial de papas fritas a partir de tubérculos cultivados en forma convencional y orgánica, siendo luego sometidos a diferentes concentraciones de gases durante su almacenamiento.

Aceptabilidad. Papas fritas provenientes de tubérculos cultivados en forma convencional $\left(\mathrm{T}_{0}\right)$ fueron evaluadas aceptables, con nota 7,3, según las cartillas estructuradas de aceptabilidad, respecto de aquellas provenientes del cultivo orgánico $\left(\mathrm{T}_{1}\right)$, las que fueron evaluadas como más que regular, con nota 6,9 en las cartillas estructuradas de aceptabilidad. La textura sería el atributo sensorial que más influyó en los panelistas, para favorecer la aceptabilidad de las papas fritas, provenientes de tubérculos cultivados en forma convencional $\left(\mathrm{T}_{0}\right)$, respecto de aquellas provenientes de tubérculos cultivados en forma orgánica $\left(\mathrm{T}_{1}\right)$.

\section{RESPECTO DEL ANÁLISIS QUÍMICO}

No existieron diferencias significativas en la composición de materia seca, almidón, proteínas, azúcares totales y azúcares reductores durante los 75 días de almacenamiento en los cuales se mantuvieron los tubérculos de papas, producidos tanto en forma convencional $\left(\mathrm{T}_{0}\right)$ como orgánica $\left(\mathrm{T}_{1}\right)$.

El contenido de materia seca, en ambas formas de cultivo $\left(\mathrm{T}_{0}\right)$ y $\left(\mathrm{T}_{1}\right)$, fue superior a un $20 \%$, cumpliendo con los requisitos mínimos de calidad exigidos en los tubérculos que se destinan a la agroindustria para elaborar papas fritas.

El contenido de almidón encontrado en tubérculos provenientes de ambas formas de cultivo $\left(\mathrm{T}_{0}\right)$ y $\left(\mathrm{T}_{1}\right)$ fue bajo, por lo cual no se recomienda el cultivar Desirée como proveedor de este importante compuesto para la agroindustria.

El contenido de proteínas fue en los tubérculos provenientes de ambas formas de cultivo $\left(\mathrm{T}_{0}\right)$ y $\left(\mathrm{T}_{1}\right)$ superior a la media de un $2 \%$, respecto de la composición de este componente en los tubérculos de papas. 
El contenido de azúcares totales encontrado en tubérculos de ambas formas de cultivo $\left(\mathrm{T}_{0}\right)$ y $\left(\mathrm{T}_{1}\right)$ fue bajo, según la literatura, siendo por este aspecto aptas para su uso en la agroindustria de papas fritas.

El contenido de azúcares reductores, obtenido en tubérculos de ambas formas de cultivo $\left(\mathrm{T}_{0}\right)$ y $\left(\mathrm{T}_{1}\right)$ fue bajo, cumpliendo con los requisitos de calidad exigidos por la agroindustria de papas fritas en particular y para cualquier tipo de producto derivado.

El cultivar Desirée y según las condiciones de este estudio, la alternativa de tipo orgánico $\left(\mathrm{T}_{1}\right)$, puede proveer al sector agroindustrial con un tubérculo de calidad, con buenos niveles de materia seca, proteínas y azúcares reductores, excepto en el contenido de almidón.

\section{RESPECTO DEL ANÁLISIS SENSORIAL.}

Según las condiciones de este estudio, no existió una preferencia particular de los panelistas por las papas fritas provenientes de tubérculos obtenidos del cultivo convencional $\left(\mathrm{T}_{0}\right)$ y orgánico $\left(\mathrm{T}_{1}\right)$, tanto en los atributos de color, textura y sabor.

El atributo color fue el mejor evaluado en las papas fritas provenientes de los tubérculos producidos en forma orgánica $\left(\mathrm{T}_{1}\right)$, la textura fue el atributo mejor evaluado en los tubérculos producidos en el cultivo convencional $\left(\mathrm{T}_{0}\right)$ y el sabor fue el atributo igualmente evaluado por los panelistas para ambas formas de cultivo $\left(\mathrm{T}_{0}\right)$ $\mathrm{y}\left(\mathrm{T}_{1}\right)$.

La consideración final de los 13 panelistas, respecto de la aceptabilidad de las papas fritas evaluadas, fue considerada como aceptable $(7,3)$ para los tubérculos producidos en forma convencional $\left(\mathrm{T}_{0}\right)$ y como más que regular $(6,9)$ en las papas fritas provenientes de los tubérculos producidos en el cultivo orgánico $\left(\mathrm{T}_{1}\right)$.

\section{LITERATURA CITADA}

ACUÑA, A. 2004. Cultivo de papa, tratamiento de semilla para disminuir la incidencia de Rizoctoniasis. Revista Tierra Adentro. Osorno. 58: 4.

ANDRADE, H. 1997. Requerimientos cualitativos para la industrialización de la papa. Revista INIAP. Quito, Ecuador. 56: 6-7.

ARTACHO, M. 1975. Evaluación de métodos para la determinación de almidón, azúcares reductores y proteínas en papas (Solanum tuberosum, L. cv Arka). Tesis para optar al título de ingeniero agrónomo, Valdivia, Chile. Universidad Austral de Chile. 65 p.

CÁCERES, P. 1991. Factores de rendimiento en la producción de almidón de papas (Solanum tuberosum L.). Tesis para optar al título de ingeniero agrónomo, Valdivia, Chile. Universidad Austral de Chile. 90 p.

CAMPOS, M.; YANOVSKY, J.; LAPEGNA, V.; PEREA, H. 2000. De los Incas a la era espacial: Impacto integrador de la liofilización de la papa. Secretaría de Agricultura, Ganadería, Pesca y Alimentos. Argentina. 70 p.

CIREN CORFO. 1997. Estudio Agrológico. Edición 114 Santiago. $55 \mathrm{p}$.

DILMER, J. 2000. Calidad de la papa para usos industriales. Corpoica, Colombia. $40 \mathrm{p}$.

EZETA, F. 2002. La competitividad en el cultivo de la papa en Latinoamérica y el Caribe: Implicaciones y retos inmediatos, conferencia magistral presentada en el XX Congreso de la ALAP, realizado en Quito, Ecuador. 50 p.

FUENTEALBA, J. 2001. La papa, una planta C3. Revista Dd La Papa. 10: 6-7.

GARCÍA, H.; GOMES, C. 2002. Investigación y transferencia de tecnologías sobre calidad de almidones, azúcares y

valoración energética de materiales de papas. Ministerio de Agricultura. Bogotá, Colombia. 60 p.

GEIGENBERGER, P. 2003. Regulation of sucrose to starch conversion in growing potato tubers. Journal of Experimental Botany. 54 (382): 457-465.

GELDRES, C. 1990. Efecto de la fertilización potásica sobre el rendimiento y calidad en el cultivo de papa (Solanum tuberosum L. (cv. Atica, Desirée)). Tesis para optar al título de ingeniero agrónomo, Valdivia, Chile. Universidad Austral de Chile. 103 p.

GOMES, R.; WONG, D. 1998. Procesamiento de la papa. Revista Agroecológica Indoagro. Lima, Perú. Año 1. 5: 4-7.

GONZÁLEZ, H. 2000. Producción de patatas: consideraciones sobre su cultivo y conservación, Revista Patatas. VictoriaGastéis. España. 5: 70.

GUGLIELMETTI, H. 1982. Almacenaje de papas, cómo mejorarlo en la zona central y centro norte, Revista La Platina 9: 16-19.

hUBER, A.; CONTRERAS, A.; HetTiCh, D. 1998. Consecuencia de la orientación de los camellones de un cultivar de papa (Solanum tuberosum sp. Tuberosum), sobre su productividad, en la zona de Valdivia. X Región, Chile. Agro Sur. 26 (2): 53-62.

INSTITUTO NACIONAL DE INVESTIGACIÓN AGROPECUARIA (INIA). 2007. Variedades de papas. Disponible en http://www.inia.cl/remehue/servicios/ insumos/cartillas_papa/desiree.cfm, Visitado el 30 marzo 2007.

HANS, A. 1998. Influencia de fitotoxicidad del cloro en el rendimiento y composición química de la papa (Solanum tuberosum L. sp Tuberosum Hawkes), destinada a uso 
industrial. Tesis para optar al título de ingeniero agrónomo, Valdivia, Chile. Universidad Austral de Chile. 70 p.

LACHMAN, J.; HAMOUZ, K.; ORSÁK, M.; PIVEC, V. 2001. Potato glycoalkaloids and their significance in plant protection and human nutrition - review. Series Rostlinná Výroba. 47 (4) Czechoslovakia. 191 p.

LOYOLA, N.; THORNTON, R.; HILLER, L.; POWER, J. 1999. Evaluación sensorial de papas fritas provenientes de tubérculos cv. Ranger Russet almacenadas en atmósfera modificada. Alimentos. 24 (1): 1-13.

MARTÍNEZ, A. 2002. Alcaloides esteroidales de solanáceas. Universidad de Antioquia, Colombia. 100 p.

OFICINA DE ESTUDIOS Y POLÍTICAS AGRARIAS (ODEPA). 2007. Estadísticas de la agricultura chilena. Disponible en $<\mathrm{http} /: / / \mathrm{www}$.odepa.minagri.gob.cl.>. Visitado el 27 abril 2007.

RODRÍGUEZ, A.; BALLESTEROS, R.; BARREIROS, J.; GONZÁLEZ, C. 2000. Evaluación sensorial de patatas cultivadas según diferentes sistemas de producción: convencional, integrado y orgánico. Revista Patata. 3-6 de julio, Vitoria-Gasteiz, Badajoz, España. 3: 16-20.

SANTOS, J. 1998. Tierra Adentro. Semilla Botánica de Papa. 2 (3): 4-7.

SANTANDER, F. 1983. Trojas para almacenaje de papas, una solución económica para evitar pérdidas durante la época de conservación del producto. Estación Experimental Carillanca. 2 (1): 16-17.

SANTIBÁÑEZ, G. 1993. Atlas Agroclimático de Chile. Santiago. $60 \mathrm{p}$.

SANTOS, J.; KALASZISH, J.; SIERRA, C. 2001. Cultivos industriales, papa. In: Sociedad Química y Minera de Chile S.A. Agenda del salitre. Undécima edición. 698 p.

STONE, H.; SIDEL, J. 1993. Sensory evaluation practices Segunda edición. Academic Press, INC, San Diego. $200 \mathrm{p}$

STOREY, R.M.J.; DAVIES, H.V. 1992. Tuber Quality, In: Harris, Paul. The potato crops. Second Edition. Editorial London: Chapman and Hall. 553 p. 